DA-2003, núms. 265-266. ESTANISLAO ARANA GARCÍA. Organización administrativa de la ciencia...

Estanislao Arana García

Profesor Titular de Derecho Administrativo

Universidad de Granada

\title{
Organización administrativa de la ciencia y tecnología en España: el Ministerio de Ciencia y Tecnología y los organismos públicos de investigación
}

SUMARIO: SUMARIO: I. BREVE INTRODUCCIÓN HISTÓRICA A LA ORGANIZACIÓN ADMINISTRATIVA DE LA CIENCIA Y TECNOLOGÍA EN ESPAÑA. 1. LA ORGANIZACIÓN ADMINISTRATIVA DE LA POLÍTICA CIENTÍFICA Y DE INVESTIGACIÓN DURANTE EL FRANQUISMO. 2. LA ORGANIZACIÓN ADMINISTRATIVA DE LA CIENCIA Y LA TECNOLOGÍA DURANTE LA TRANSICIÓN A LA DEMOCRACIA. II. LA ORGANIZACIÓN ADMINISTRATIVA DE LA CIENCIA Y LA TECNOLOGÍA EN LA ACTUALIDAD. 1. El MiNisTERIO DE CIENCIA Y TECNOLOGÍA. 2. LA COORDINACIÓN ADMINISTRATIVA EN MATERIA DE CIENCIA Y TECNOLOGÍA: LA COMISIÓN INTERMINISTERIAL DE Ciencia Y TeCNOlogía. 3. OTROS ÓRganos de la ADMINISTRACión CENTRAL CON COMPETENCIAS EN MATERIA DE CIENCIA Y TECNOLOGÍA. III. LA ADMINISTRACIÓN INSTRUMENTAL EN MATERIA DE CIENCIA Y TECNOLOGÍA: LOS ORGANISMOS PÚBLICOS DE INVESTIGACIÓN Y EL RÉGIMEN JURÍDICO DE SU PERSONAL. 1. RÉGIMEN JURÍDICO COMÚN DE LOS ORGANISMOS PÚBLICOS DE INVESTIGACIÓN. 2. LA ADMINISTRACión INSTRUMENTAL ESPAÑOLA DE CIENCIA Y TECNOLOGÍA. 3. RÉGIMEN JURÍDICO DEL PERSONAL DE LOS OPIS. IV. CIENCIA Y TECNOLOGÍA Y COMUNIDADES AUTÓNOMAS. 1. LA DISTRIBUCIÓN DE COMPETENCIAS ENTRE EL ESTADO Y LAS COMUNIDADES AUTÓNOMAS EN CIENCIA Y TECNOLOGÍA. 2. ORGANIZACIÓN Y POLÍTICA LEGISLATIVA EN MATERIA DE CIENCIA Y TECNOLOGÍA EN LAS DifERENTES COMUnidAdES AutónOMAS.

I. BREVE INTRODUCCIÓN HISTÓRICA A LA

ORGANIZACIÓN ADMINISTRATIVA DE LA CIENCIA Y TECNOLOGÍA EN ESPAÑA

La forma en que se organiza el poder público administrativo para cumplir con sus obligaciones en un determinado ámbito no es para 
nada baladí pues refleja el grado de compromiso real del Estado ante una responsabilidad pública.

Antes de conocer el estado de la cuestión de la organización administrativa de la ciencia y la tecnología en nuestros días, resulta interesante conocer, siquiera brevemente, la más reciente historia de esta realidad. Este escueto repaso histórico abarcará fundamentalmente desde el fin de la Guerra Civil hasta la promulgación de la CE y de la llamada Ley de la Ciencia ${ }^{1}$.

En este período histórico vamos a ver reflejados los pilares de la organización administrativa en la actualidad así como el origen de la mayor parte de los problemas de la organización de la ciencia y la tecnología. Fundamentalmente, el esquema de la organización administrativa de esta primera fase se reconduce, en primer lugar, a una estructura, más o menos compleja, dentro de los diferentes Ministerios de la Administración central y, en segundo término, a la creación de una, todavía rudimentaria, Administración instrumental basada, esencialmente, en los llamados organismos públicos de investigación que nacen con el CSIC y que poco a poco van a ir creciendo y multiplicándose.

\section{LA ORGANIZACIÓN ADMINISTRATIVA DE LA POLÍTICA CIENTÍFICA Y DE INVESTIGACIÓN DURANTE EL FRANQUISMO}

Los orígenes de una auténtica política científica de los Estados modernos hay que situarlos, en primer lugar, en los momentos previos a la II Guerra Mundial donde pudo comprobarse que los Estados que más apoyaron la investigación y la ciencia se vieron directamente favorecidos en la Guerra por los avances conseguidos en este campo.

En la España de la posguerra no había nada que se pareciese a lo que hoy se podría denominar una política científica y tecnológica explícita, los efectos humanos y materiales de la guerra y, sobre todo, el exilio explican fácilmente esta situación. A partir de 1939 la clave para la acción estatal sobre la ciencia se situó en el Consejo Superior de Investigaciones Científicas (CSIC), que se convirtió en el centro del sistema científico-técnico de la posguerra. La iniciativa de creación del CSIC procede del Ministerio de Educación Nacional y responde al intento de reconstruir las elites investigadoras del país, desaparecidas en la guerra

1 Sobre la evolución de las relaciones entre el Estado y la Ciencia y Tecnología pueden verse, con carácter general, los trabajos de R. MARTín MATEO, La Administración de la Ciencia, CAICY'T, Madrid, 1980; L.M. SANZ MENÉNDEZ, Estado, ciencia y tecnología en España (1939-1997), Edit. Alianza, Madrid 1997; M. CuETo PÉREZ, Régimen jurídico de la investigación científica: la labor investigadora en la Universidad, Edit. Cedecs, Barcelona 2002 y A. CALONGE VELÁZQueZ, Administración e investigación, Edit. Mc Graw Hill, Madrid 1996. 
DA-2003, núms. 265-266. ESTANISLAO ARANA GARCÍA. Organización administrativa de la ciencia...

o en el exilio y, quizá, colateralmente, de controlar y dominar su orientación intelectual e ideológica² ${ }^{2}$.

La actitud oficial sobre la posición del Estado ante la investigación se ve reflejada claramente en el preámbulo de la Ley de 24 de noviembre de $1939^{3}$, de creación del Consejo Superior de Investigaciones Científicas. En esta norma se declara que el Estado «debe ser el órgano fundamental de impulso y apoyo» a la investigación científica y, en consecuencia, a él «corresponde la coordinación de cuantas actividades e instituciones están destinadas a la creación de la ciencia». La investigación nacional necesitaba de ordenación, tarea que se atribuía al recién creado «órgano de nueva contextura, cuya misión era exclusivamente coordinadora y estimulante, sin aspirar a mediatizar los centros e instituciones que con vida propia se desarrollan».

Casi toda la política científica del régimen franquista empezó girando en torno al CSIC. Con la creación de este órgano se trataba también de reemplazar la estructura y las actividades de la Junta para la Ampliación de Estudios e Investigaciones Científicas (JAE). Se quería jugar un papel análogo pero de signo contrario al que la Junta para la Ampliación de Estudios había desempeñado en la historia anterior a la Guerra Civil. Los centros antes dependientes de la Junta para la Ampliación de Estudios y de la Fundación Nacional de Investigaciones Científicas y Ensayos y Reformas (FNICER) pasaron a depender directamente de ese órgano de «nueva contextura», encargado de fomentar, orientar y coordinar la investigación científica nacional ${ }^{4}$. Sin embargo, poco a poco, a partir de la creación del CSIC, todos los Ministerios se lanzaron a la creación de diferentes centros de investigación, momento en el que hay que situar el origen de la descoordinación de la política científica como mal endémico de nuestro país a lo largo de su más reciente historia.

Con el desarrollismo de finales de los cincuenta y, sobre todo, en los años sesenta la política científica y tecnológica en España va a experimentar algunos cambios. La preocupación gubernamental de la época por los problemas de coordinación y de falta de jerarquía y orden en el sistema de la toma de decisiones en el ámbito de la Ciencia y la Tecnología se refleja en el Decreto de 7 de febrero de 1958 que, modificando la Ley de 24 de noviembre de 1939 de creación del CSIC, separa las funciones de «fomentar y orientar la investigación asignadas al CSIC del objetivo de coordinar la investigación». La coordinación de la inves-

2 L. SANZ MENÉndez, Estado, Ciencia ..., cit. anteriormente, pp. 120 y 121.

3 Esta Ley sería retocada y modificada, entre otras, por las Leyes de 22 de julio de 1942 y de 27 de diciembre de 1947.

${ }^{4}$ L. SANZ MENÉNDEZ, Estado, ciencia ..., cit. anteriormente, p. 123. 
tigación «ha de alcanzarse promoviendo el mutuo conocimiento de actividades científicas en los centros de investigación dependientes de los diversos ministerios, el estudio de planes conjuntos de trabajo y la puesta a disposición de todos y de la industria misma del material básico y de la documentación que las instituciones del CSIC han ido reuniendo en sistemática ordenación a través de una amplia red de relaciones internacionales...».

Este Decreto crea la Comisión Asesora de Investigación Científica Técnica «con la misión de asesorar en la programación y desarrollo de los planes de investigación científica técnica de interés nacional» (art. 1). Esta Comisión tenía un carácter exclusivamente político-planificador ya que el artículo 6 señalaba que la misma no podía tener centros propios de investigación, sino que las investigaciones programadas de acuerdo con sus propuestas se desarrollarán precisamente en los organismos de investigación científica ya constituidos. Idea que refleja la nueva política científica en la que se pretende sustituir la acción pública mediante la creación de centros por la de actuar a través de proyectos o programas promovidos por los organismos burocráticos del Estado 5 .

Otra norma que demuestra el impulso que se pretendía dar a la ciencia y la tecnología en estos años, destacando, además, el intento de reconducir toda la política científica de estos años al desarrollo económico del país, es el Decreto 1765/1961, de 22 de septiembre, por el que se creaban Asociaciones de Investigación, como «medio de estimular el desarrollo de la investigación en la industria».

Mediante Decreto 896/1963, de 25 de abril, se creó la Comisión Delegada del Gobierno de Política Científica, que perseguía la reorganización del sistema de toma de decisiones y la asignación de recursos. El Decreto insistía en la necesidad de desarrollar «la coordinación y colaboración estrecha de Ministerios interesados en (...) materia de investigación científica y técnica». Según el artículo 1 del Decreto, la Comisión Delegada se había creado «para orientar y coordinar la política del Estado en el fomento de la investigación científica y técnica». A diferencia de la Comisión Asesora cuyo soporte era facilitado por el CISC, la nueva Comisión Delegada estaba dotada de la infraestructura administrativa y técnica del Ministerio de la Subsecretaría de la Presidencia del Gobierno.

Por Decreto de 16 de octubre de 1964 se creó el Fondo Nacional para la Investigación Científica como conmemoración del XXV ani-

${ }^{5}$ El instrumento principalmente utilizado para cumplir con este objetivo fue el de los planes de desarrollo. Técnica iniciada por los gobiernos desarrollistas del franquismo, así, a finales de 1963 se aprobó el primero, cuya vigencia fue de 1964 a 1967, que en el campo de la investigación y el desarrollo tuvo como objetivo fundamental el impulso de la infraestructura científica. 
DA-2003, núms. 265-266. ESTANISLAO ARANA GARCÍA. Organización administrativa de la ciencia...

versario de la creación del CSIC, «con el fin de disponer de recursos excepcionales destinados a impulsar y estimar acciones combinadas de investigación científica que no pudieran ser atendidas con los medios regulares de financiamiento de los centros de investigación» (art. 1). La administración de este Fondo correspondía a la Comisión Delegada de Política Científica que resolvía las solicitudes de financiación, previo informe de la Comisión Asesora (art. 6).

Con estas acciones puede decirse que en la Administración española se desarrollaban, por primera vez en su historia, competencias y colectivos de burócratas cuyo campo de acción era la ciencia, frente a la situación anterior donde solamente investigadores y responsables de los centros de investigación jugaban papeles definitivos ${ }^{6}$.

Aunque sea brevemente, merecen ser destacados otros momentos y normas fundamentales en la evolución de la organización administrativa de la ciencia y tecnología en estos años; así, en 1966 se rebautizó el Ministerio de Educación como Ministerio de Educación y Ciencia, dotándose de una subsecretaría de Enseñanza Superior e Investigación que sería suprimida en 1967 en un momento de austeridad económica.

El Decreto 3055/1966 modificó el reglamento del CSIC y el Decreto 2179/1967, de 19 de agosto, sobre el reglamento de coordinación entre centros de enseñanza superior y de investigación, por los que se otorgaba al CSIC un papel más claro en la estrategia y en la política científica del Estado. El II Plan de Desarrollo (1968-1971) introducía medidas para promover el crecimiento de los efectivos de investigación y estimular la expansión de la investigación en las empresas. Precisamente para el fomento de la investigación en la industria, el Decreto 1410/68, de 6 de junio, creó los llamados Planes Concertados que tenían este objetivo como fundamental mediante la financiación por parte del Estado del $50 \%$ de los costes de los proyectos de I+D. El Decreto 2011/1971, de 23 de julio, convirtió la Comisión Asesora en el órgano de trabajo de la Comisión Delegada del Gobierno para Política Científica. A esta Comisión correspondería «como órgano de enlace entre los distintos centros estatales de Investigación Aplicada y Tecnológica y dicha Comisión Delegada, la propuesta a ésta de los criterios generales para la unificación de los planes de los organismos dependientes de los distintos ministerios y la coordinación de los mismos con los programas de investigación científica y desarrollo tecnológico contenidos en los planes de Desarrollo Económico y Social» (art. único). El III Plan de Desarrollo (1972-1975) acentuó la orientación hacia el desarrollo tecnológico y se centró en «grandes proyectos» de carácter sectorial. Sin embargo, al igual que los anteriores, este Plan contó con la debilidad

${ }^{6}$ L. SANZ MENÉNDEZ, Estado, ciencia ..., cit. anteriormente, p. 142. 
fiscal del Estado que le hacía no disponer de medios económicos suficientes como para poder destinar de verdad a la investigación los fondos económicos prometidos en los diversos planes de desarrollo.

En esta época las instituciones que desarrollaban la política de I + D eran la Comisaría del Plan de Desarrollo y el Ministerio de Educación y Ciencia. El Ministerio de Industria había estado al margen de la promoción tecnológica -quizá con la única excepción del desarrollo de la energía nuclear a través de la JEN. Además, la actuación del Ministerio de Industria en este ámbito estaba mediatizada por la existencia del INI, que mantenía algunos centros de investigación importantes como, por ejemplo, el CETA (Centro de Estudios Técnicos de la Automoción), CETME o la Empresa Nacional Calvo Sotelo.

En definitiva, al final del franquismo la situación en la que a nivel organizativo se encontraba la ciencia y la tecnología en nuestro país era la de una dependencia casi absoluta de todos los operadores de I+D de los diferentes Ministerios, con el CSIC jugando un papel relevante en el conjunto del sistema y con el subdesarrollo de la investigación en la Universidad.

\section{LA ORGANIZACIÓN ADMINISTRATIVA DE LA CIENCIA Y LA TECNOLOGÍA DURANTE LA TRANSICIÓN A LA DEMOCRACIA}

En unos momentos política y económicamente tan delicados como los que se vivieron en la transición a la democracia, no se produjeron novedades especialmente destacables en el ámbito de la organización de la ciencia y la tecnología en España. En todo caso, señalar que tuvo lugar la liquidación del Plan de Desarrollo y el Ministerio de Educación y Ciencia intentó atraer para sí las competencias e instrumentos de acción del Estado en materia de política científica y tecnológica.

Como normas organizativas destacables de esta época podemos señalar, por ejemplo, el Decreto 1256/1974, de 25 de abril, que modificó los Planes concertados para ampliar su aplicación a empresas públicas o el Decreto 3534/1975, de 5 de diciembre, que adscribió el CSIC y el resto de organismos autónomos al Ministerio de Educación y Ciencia.

El Decreto de 5 de agosto de 1977 creó el Centro para el Desarrollo Tecnológico Industrial (CDTI). Este organismo nació con el objetivo de desarrollar proyectos de investigación industrial que se financiasen a través de convenios con el Banco Mundial, que otorgaba una línea de crédito destinada al desarrollo tecnológico de la industria española. Se atribuyó al CDTI «el impulso y promoción del desarrollo tecnológico de la producción industrial española». 
El RD 62/1977, de 21 de enero, aprobó la reorganización interna del CSIC y el RD 3450/1977 aprobó su reglamento orgánico. El RD 3157/1977, de 28 de octubre, aprobó la actualización de la composición de la Comisión Delegada del Gobierno de Política Científica. El RD 2412/1979, de 5 de octubre, produjo la reorganización de las competencias y funcionamiento de la Comisión Asesora de la Investigación Científica y Técnica (CAICYT), bajo la dependencia orgánica del Ministerio de Universidades e Investigación, a la que correspondería la elaboración de las directrices generales para el desarrollo de la investigación científica y técnica, así como la propuesta de distribución de recursos para promover dicho desarrollo. La Comisión será, a estos efectos, el órgano asesor y de trabajo de la Comisión Delegada del Gobierno de Política Científica» (art. 1).

El RD 342/1980, de 11 de enero, de planes concertados de investigación, modificó el 1410/1968, de 6 de junio, para adaptar este mecanismo a la nueva configuración estructurada en la CAICYT. Con la misma finalidad, el RD 2516/1980, de 17 de octubre, de modificación de los Decretos 1765/1961 y 1012/1970 sobre Asociaciones de investigación, cambió la regulación de las asociaciones de investigación.

En el área del Ministerio de Industria se produjo una reorganización del consejo rector del CDTI mediante el RD 2904/1980, de 4 de noviembre, reforzando su dependencia de la estructura orgánica del ministerio y, a la vez, ampliando los ministerios que estaban anteriormente representados.

Ésta era, a grandes trazos, la situación de la organización administrativa de la ciencia y la tecnología en España prácticamente hasta la llegada de la Constitución de 1978, veamos a continuación los cambios más importantes que en este ámbito se producen desde este momento hasta la actualidad.

\section{LA ORGANIZACIÓN ADMINISTRATIVA DE LA CIENCIA Y LA TECNOLOGÍA EN LA ACTUALIDAD}

El apoyo público a la ciencia y tecnología sufrió un definitivo respaldo con el artículo 44.2 de la CE, en el que se dice que «Los poderes públicos promoverán la ciencia y la investigación científica y técnica en beneficio del interés general» ${ }^{7}$.

Para cumplir con este mandato, institucionalmente la actual Administración Central del Estado ha decidido centralizar todas las compe-

7 Sobre el alcance y significado de este precepto puede verse A. CALONGE VELÁZQUEZ, Administración e investigación, cit. anteriormente, pp. 1 y ss. y M. CUETO PÉREZ, Régimen jurídico..., cit. anteriormente, pp. 65 y ss. 
tencias en el ámbito de la ciencia y la tecnología al máximo nivel organizativo, esto es, creando por primera vez en la historia un Ministerio específico de Ciencia y Tecnología.

Además del Ministerio de Ciencia y Tecnología y de todos los órganos bajo él dependientes, el esqueleto organizativo de la ciencia y tecnología se dibuja en la Ley 13/1986, de 14 de abril, de Fomento y Coordinación General de la Investigación Científica y Técnica, también conocida como Ley de la Ciencia ${ }^{8}$.

Junto a la regulación del Plan Nacional de Investigación como figura central de toda la ciencia y la investigación en nuestro país, desde un punto de vista organizativo, en esta Ley se establece el régimen jurídico de los órganos que dentro de la Administración Central del Estado ejercen competencias en este ámbito, sobre todo, las de coordinación; por último, la Ley pretende unificar el régimen jurídico de la mayor parte de la que podríamos denominar «Administración instrumental o institucional de la Ciencia y Tecnología en España», esto es, de los organismos públicos de investigación.

\section{El MiNiSTERIO DE CIENCIA Y TECNOLOGÍA}

El artículo 5 del Real Decreto 557/2000, de 27 de abril, de reestructuración de departamentos ministeriales, creó el Ministerio de Ciencia y Tecnología como departamento responsable de la política científica, tecnológica de las telecomunicaciones y el impulso de la sociedad de la información. Dicho precepto crea como órganos superiores del Departamento la Secretaría de Estado de Política Científica y Tecnológica y la Secretaría de Estado de Telecomunicaciones y para la Sociedad de la Información.

Son, por tanto, dos los grandes ámbitos de responsabilidad que tiene encomendados este Ministerio: la política científica y la política tecnológica de las telecomunicaciones y el impulso de la sociedad de la información. Dado el objeto de estudio de este trabajo, me centraré en el ámbito de la política científica y de investigación.

El RD 696/2000, de 12 de mayo, establece la estructura orgánica básica del Ministerio de Ciencia y Tecnología. El artículo $1^{\circ}$ de dicha norma establece que el Ministerio de Ciencia y Tecnología se estructura en, lo que a este trabajo interesa, en los siguientes órganos superiores y directivos: «1. La Secretaría de Estado de Política Científica y Tecnológica, de la que dependen los siguientes órganos directivos: a) La Secretaría General de Política Científica, con rango de Subsecretaría, a la

${ }^{8}$ Ley modificada, entre otras, por las Leyes 24/2001, de 27 de diciembre; 23/2001, de 27 de diciembre; 12/2001, de 9 de julio; 14/2000, de 29 de diciembre; 13/2000, de 28 de diciembre; 5/2000, de 16 de octubre; 50/1998, de 30 de diciembre y 13/1996, de 30 de diciembre. 
DA-2003, núms. 265-266. ESTANISLAO ARANA GARCÍA. Organización administrativa de la ciencia...

que corresponden las funciones de coordinación de las actuaciones relativas a las grandes instalaciones científicas de carácter estatal. b) La Dirección General de Investigación, a la que corresponden las competencias relacionadas con el fomento y la difusión del conocimiento científico y la gestión de los recursos públicos estatales y comunitarios a que dé lugar esta actividad. c) La Dirección General de Política Tecnológica, a la que corresponden las competencias en materia de integración de la investigación científica y el desarrollo tecnológico en el ámbito empresarial, así como las relacionadas con las empresas industriales, en especial en materia de seguridad, calidad y normalización... 3. La Subsecretaría de Ciencia y Tecnología, de la que depende la Secretaría General Técnica»?

El artículo 1.5 de esta misma norma señala que «La Secretaría de Estado de Política Científica y Tecnológica asume las competencias en materia de investigación científica y desarrollo tecnológico, que correspondían a la Secretaría de Estado de Educación, Universidades, Investigación y Desarrollo y a la Oficina de Ciencia y Tecnología, así como las atribuidas a la Dirección General de Industria y Tecnología». Es decir, se trata por todos los medios de unificar o centralizar en este Ministerio las competencias en materia de investigación y desarrollo que hasta el momento se encontraban muy dispersas aunque eran fundamentalmente los Ministerios responsables de Educación y de Industria las que concentraban la mayor parte de las competencias de este sector.

Por su parte, el RD 1451/2000, de 28 de abril, desarrolla la estructura orgánica básica del Ministerio de Ciencia y Tecnología. Además de concretar las funciones de la Secretaría de Estado de Política Científica y Tecnológica, estructura ésta en los siguientes órganos directivos que dependen de ella: a) Secretaría General de Política Científica. b) Dirección General de Investigación. c) Dirección General de Política Tecnológica. Igualmente, está adscrita al Ministerio de Ciencia y Tecnología, a través de la Secretaría de Estado de Política Científica y Tecnológica, la Agencia Nacional de Evaluación y Prospectiva.

\section{LA COORDINACIÓN ADMINISTRATIVA EN MATERIA DE CIENCIA Y TECNOLOGÍA: LA COMISIÓN INTERMINISTERIAL DE CIENCIA Y TECNOLOGÍA}

Para la resolución de lo que anteriormente calificamos como uno de los males endémicos de la ciencia y la tecnología en España, esto es,

9 Subsecretaría creada mediante el Real Decreto 574/2000, de 5 de mayo. El RD 1451/2000, de 28 de julio, precisa que la Secretaría General de Política Científica está integrada por los siguientes órganos directivos, con nivel orgánico de subdirección general: a) Subdirección General de Ordenación Normativa y Coordinación. b) Subdirección General de Planificación. c) Subdirección General de Seguimiento de Actividades, Programas y Proyectos. 
la coordinación de toda acción pública en este ámbito, la Ley de la Ciencia creó la Comisión Interministerial de Ciencia y Tecnología (CICYT), que asumía un conjunto de competencias para la acción pública en el campo de la investigación y el desarrollo tecnológico. Esta Comisión acabó pareciéndose a su antecesora la Comisión Asesora de Investigación Científica y Técnica (CAICYT), aunque acumulando algunas de las competencias atribuidas a la extinta Comisión Delegada del Gobierno para Política Científica.

La intención gubernamental al crear la Comisión Interministerial era la existencia de una instancia administrativa intermedia que tenía como objetivo frenar las luchas competenciales entre los ministerios y crear un campo común de negociación. La atribución de estas competencias a este órgano hizo que la política científica y tecnológica se convirtiera en un campo interministerial, un lugar de negociación permanente sobre la acción pública, aunque con la posibilidad de un ejercicio hegemónico por parte de alguno de los ministerios, especialmente del que depende administrativamente la CICYT ${ }^{10}$.

La Comisión Interministerial de Ciencia y Tecnología es, según el artículo 7 de la Ley, el «órgano de planificación, coordinación y seguimiento del Plan Nacional» y que «estará formada por los representantes de los departamentos ministeriales que nombre el gobierno». Se convierte, pues, la CICYT en uno de los órganos administrativos más importantes de la Ciencia y Tecnología en nuestro país, órgano que se regula mediante el Real Decreto 1786/2000, de 27 de octubre ${ }^{11}$.

Este órgano que en la actualidad está adscrito al Ministerio de Ciencia y Tecnología, tiene la siguiente composición: A) Presidente: el Presidente del Gobierno. B) Vicepresidente: el Ministro de Ciencia y Tecnología. C) Vocales: a) El Ministro de Asuntos Exteriores. b) El Ministro de Hacienda. c) La Ministra de Educación, Cultura y Deporte. d) El Secretario de Estado de Defensa. e) El Secretario de Estado de Economía, de la Energía y de la Pequeña y Mediana Empresa. f) El Secretario de Estado de Política Científica y Tecnológica, quien actuará como Secretario. g) El Secretario general de Gestión y Cooperación Sanitaria. h) El Director del Departamento de Bienestar y Educación de la Presidencia del Gobierno.

Destacar la importancia de que la Comisión Interministerial cuente como presidente con el Presidente del Gobierno. Esto supone un es-

10 L. SANZ MENÉNDEZ, Estado, ciencia..., cit. anteriormente, p. 280.

11 Esta composición ha de adaptar la que establecía el Real Decreto 80/1997, de 24 de enero, por el que se determina la composición de la Comisión Interministerial de Ciencia y Tecnología, a la nueva creación del Ministerio de Ciencia y Tecnología, Departamento ministerial responsable de la política de fomento y coordinación general de la investigación científica y técnica y del desarrollo tecnológico. 
paldarazo organizativo muy importante a este fundamental órgano de la Ciencia y Tecnología en España que corrige disfunciones jerárquicas de anteriores regulaciones ${ }^{12}$.

La Comisión Interministerial cuenta en su estructura con un órgano ejecutivo denominado Comisión permanente. Comisión permanente cuya composición fue acordada mediante el Acuerdo del Consejo de Ministros de 9 de febrero de 2001 y que fue publicada en el $B O E$ de 26 de junio de $2001^{13}$.

En cuanto a las funciones de la Comisión Interministerial, en primer lugar, hay que referirse a que es el órgano responsable de la elaboración del Plan Nacional «en coordinación con los órganos de planificación económica de la Administración del Estado» (art. 6). La CICY'T se convirtió en titular de las competencias, a través del Plan Nacional de I+D, para establecer los grandes objetivos de la investigación y, por tanto, en responsable de la coordinación de esos objetivos; además, era el garante de la coordinación de las acciones de los organismos dependientes de la Administración del Estado y el mecanismo para la toma de decisiones, como soporte institucional de la negociación entre los diferentes Ministerios con los intereses en el campo de la $\mathrm{I}+\mathrm{D}^{14}$.

Siguiendo con la fundamental labor de coordinación que la Ley encomienda a la CICYT, su artículo 7.3 le atribuye, además de la competencia para la elaboración del Plan Nacional, las siguientes funciones:

«a) Proponer la asignación de los fondos públicos y de aquellos privados acordados, destinados a los diferentes programas que integren el Plan Nacional, y atribuir, cuando proceda, la gestión y ejecución de

${ }^{12}$ Ya corrigió esta situación la Ley de acompañamiento de los presupuestos generales del Estado para 1996, que en su art. 155 procedía a modificar la Ley 13/1986, de 14 de abril, de Fomento y Coordinación General de la Investigación Científica y Técnica, en los apartados 1 y 2 del art. 7 que aumentó el rango político de la Comisión que pasaría a ser el presidente del Gobierno.

13 La Comisión Permanente de la Comisión Interministerial de Ciencia y Tecnología tendrá la siguiente composición: 1. Presidenta: La Ministra de Ciencia y Tecnología. 2. Vicepresidente: El Secretario de Estado de Política Científica y Tecnológica. 3. Vocales: a) El Secretario de Estado para la Cooperación Internacional y para Iberoamérica. b) El Secretario de Estado de Defensa. c) La Secretaria de Estado de Presupuestos y Gastos. d) El Secretario de Estado de Educación y Universidades. e) El Secretario de Estado de Economía, de la Energía y de la Pequeña y Mediana Empresa. f) El Secretario de Estado de Telecomunicaciones y para la Sociedad de la Información. g) La Subsecretaria de Presidencia. h) El Secretario general de Gestión y Cooperación Sanitaria. i) El Director del Departamento de Bienestar y Educación del Gabinete del Presidente del Gobierno. 4. Secretario sin voto: el Director general de Investigación.

14 L. SAnz Menéndez, Estado, ciencia..., cit. anteriormente, p. 261. Para intentar que las decisiones a tomar por la CICYT fuesen sensibles a las necesidades de la sociedad, se creó el Consejo Asesor para la Ciencia y Tecnología (art. 9), para vincular ésta a «la comunidad científica, los agentes sociales y los responsables de programar la actividad científico/investigadora» y con el objetivo de favorecer «la participación de la comunidad científica y de los agentes económicos y sociales en la elaboración, seguimiento y evaluación del Plan Nacional». 
los mismos, así como determinar su duración; b) Coordinar las actividades de investigación que los distintos Departamentos ministeriales y organismos de titularidad estatal realicen en cumplimiento del Plan Nacional, así como conocer las actuaciones de apoyo y asistencia técnica de aquellos que tengan relación con las mencionadas actividades; c) Coordinar e integrar en el Plan Nacional los proyectos de investigación científica y desarrollo tecnológico, financiados con fondos procedentes de tarifasfijadas por el Gobierno; d) Evaluar el cumplimiento del Plan Nacional y de los programas presupuestarios correspondientes al mismo, sin perjuicio de las competencias propias de los demás órganos de la Administración; e) Coordinar con el Plan Nacional las transferencias tecnológicas que se deriven del programa de adquisiciones del Ministerio de Defensa y de cualquier otro Departamento ministerial; f) Presentar al Gobierno para su elevación a las Cortes Generales una Memoria anual relativa al cumplimiento del Plan $\mathrm{Na}$ cional, que comprenda, en su caso, las propuestas de rectificación que estime necesario introducir en los mismos; g) Orientar la política de formación de investigadores en todos sus niveles, proponer medidas para el fomento del empleo de los mismos y facilitar su movilidad en los ámbitos investigador y productivo; h) Recabar, coordinar y suministrar la información científica y tecnológica necesaria para el cumplimiento del Plan Nacional; i) Elevar al Gobierno las propuestas que estime necesarias para asegurar el desarrollo y cumplimiento del Plan Nacional».

Por su parte, el artículo 8.2 atribuye a la CICY'T las relaciones científicas internacionales, especialmente «la coordinación y seguimiento de los programas internacionales de investigación científica y desarrollo tecnológico, con participación española», para lo que asumirá una serie de funciones que el precepto expresamente prevé.

Para poder cumplir con las numerosas e importantes competencias, el artículo 7.2 de la Ley 13/1986, en la versión dada a este precepto por la Ley 14/2000, de 29 de diciembre, atribuyó al Ministerio de Ciencia y Tecnología, como Departamento responsable de la política de fomento y coordinación general de la investigación científica y técnica las funciones de apoyo tanto de la Comisión Interministerial como, lógicamente, de su Comisión permanente. Además, en este precepto se trató de reforzar los medios personales y materiales de la Comisión, señalando que

«El Ministerio de Ciencia y Tecnología, previa autorización del organismo correspondiente, podrá adscribir temporalmente a tiempo completo o parcial, personal científico, expertos en desarrollo tecnológico y otros especialistas relacionados con actividades de investigación científica y desarrollo tecnológico, que presten servicios en Departa- 
mentos ministeriales, Comunidades Autónomas, universidades, organismos públicos de investigación y entidades públicas o privadas. La adscripción se producirá con reserva de puesto de trabajo, excepto en el caso de que el personal prestara servicios en entidades privadas. De las adscripciones efectuadas deberá informarse a la Comisión permanente en la primera reunión que ésta celebre. Los departamentos ministeriales, organismos y órganos de titularidad estatal también podrán adscribir para colaborar en la elaboración, evaluación, seguimiento y gestión de los programas que la Comisión interministerial les encomiende, personal científico, expertos en desarrollo tecnológico y otros especialistas relacionados con actividades de $I+D$ en las mismas condiciones que el órgano citado en el párrafo anterior y previa autorización expresa de la Comisión Interministerial de Ciencia y Tecnología. La adscripción a tiempo parcial del personal mencionado anteriormente será compatible con el desempeño, igualmente en régimen de prestación a tiempo parcial, del puesto de trabajo que vinieran ocupando. También podrán controlar, por tiempo no superior a la duración del programa, a cualquier tipo de personal no adscrito al sector público, conforme a lo establecido en el artículo 15.1, párrafo a) del Estatuto de los Trabajadores. La Comisión podrá solicitar el asesoramiento de los órganos de planificación, coordinación y seguimiento de investigación de las Administraciones públicas» ${ }^{15}$.

\section{OTROS ÓRGANOS DE LA ADMINISTRACIÓN CENTRAL CON COMPETENCIAS EN MATERIA DE CIENCIA Y TECNOLOGÍA}

La organización administrativa estatal en materia de Ciencia y Tecnología no termina con el Ministerio de Ciencia y Tecnología ni con el principal órgano de coordinación de competencias que crea la Ley de la Ciencia. Para tratar de ayudar a uno y otro tipo de órganos, la Ley 13/1986 crea una serie de órganos que tratan de facilitar la comunicación de la política científica y tecnológica con la sociedad, especialmente con las empresas y en el ámbito administrativo, con el resto de Administraciones públicas presentes en nuestro país.

15 Para M. Cueto PÉREZ, Régimen jurídico..., cit. anteriormente, p. 127, las competencias atribuidas a los diferentes órganos del Ministerio de Ciencia y Tecnología por el RD 1451/2000, de 28 de julio, entran en contradicción con lo dispuesto en la Ley 13/1986, a la vez que incumplen la prohibición establecida en el art. 11 de la Ley 30/1992 que impide la creación de nuevos órganos que supongan duplicación de los ya existentes si, al mismo tiempo, no se suprime o restringe debidamente la competencia de éstos. Esta cuestión, en relación con la CICYT sólo podría hacerse con la reforma de la Ley 13/1986, sin embargo, la llevada a cabo por al Ley 14/2000, de 29 de diciembre, mantiene las mencionadas contradicciones al no modificar las competencias de la CICYT. 
DA-2003, núms. 265-266. ESTANISLAO ARANA GARCÍA. Organización administrativa de la ciencia...

Para la gestión de la política científica y de investigación con las empresas el art. 10 de la Ley 13/1986 y a los efectos de promover la implantación de nuevas tecnologías creó el Centro para el Desarrollo Tecnológico e Industrial que ejercerá, en relación con el Plan Nacional, las siguientes funciones:

a) Evaluar el contenido tecnológico y económico-financiero de los proyectos en los que intervengan Empresas; b) Contratar con las Universidades, Organismos públicos de investigación y Empresas la promoción de la explotación comercial de las tecnologías desarrolladas por ellas; c) Colaborar con la Comisión Interministerial de Ciencia y Tecnología en la obtención de los adecuados retornos científicos, tecnológicos e industriales de los Programas Internacionales con participación española y gestionar los que, de acuerdo con lo establecido en el artículo 8, aquélla le encomiende.

Este Centro para el Desarrollo Tecnológico e Industrial gestionará sus recursos de acuerdo con las orientaciones y criterios que se determinen en el Plan Nacional ${ }^{16}$.

Por su parte, el artículo 9 de la Ley creó el Consejo Asesor para la Ciencia y la Tecnología a los efectos de promover la participación de la comunidad científica y de los agentes económicos y sociales en la elaboración, seguimiento y evaluación del Plan Nacional. Al Consejo Asesor para la Ciencia y la Tecnología le corresponden las siguientes funciones: a) Proponer objetivos para su incorporación al Plan Nacional; b) Asesorar a la Comisión Interministerial de Ciencia y Tecnología en la elaboración del Plan Nacional; c) Informar, previamente a su remisión al Gobierno, el Plan Nacional elaborado por la Comisión Interministerial de Ciencia y Tecnología, así como sobre el grado de su cumplimiento, especialmente en lo que se refiere a su repercusión social y económica; d) Elevar a la Comisión Interministerial de Ciencia y Tecnología propuestas de modificación del Plan Nacional a las que se hace referencia en la letra f) del apartado tercero del artículo séptimo; e) Emitir cuantos informes y dictámenes le sean solicitados por la Comisión Interministerial de Ciencia y Tecnología o por los Organismos responsables de la política científica en las Comunidades Autónomas.

El Consejo Asesor para la Ciencia y la Tecnología se regula mediante el Real Decreto 413/2001, de 20 de abril que en su artículo $3^{\circ}$ establece su composición ${ }^{17}$.

16 El RD 1406/1986, de 6 de junio, aprueba el Reglamento del Centro para el Desarrollo Tecnológico Industrial. Real Decreto, a su vez, modificado en parte por el RD 2100/1998, de 25 de septiembre y RD 1270/1988, de 28 de octubre.

17 «El Consejo Asesor está constituido por el Presidente, el Vicepresidente y los Consejeros. 2. El Presidente del Consejo Asesor es la Ministra de Ciencia y Tecnología. 3. El Vicepresidente del Consejo Asesor es el Secretario de Estado de Política Científica y Tecnológica del Ministerio de Ciencia y Tecnología. 4. Serán Consejeros del Consejo Asesor para la Ciencia y la Tecnología, designados por el Presidente del Consejo Asesor: a) Diez representantes de la comunidad científica, de los que cuatro serán Rectores de universidad y dos Presidentes o Directores de organismos públicos de investigación. b) Tres representantes de las asociacio- 
Por último, en aras de garantizar la coordinación de la política científica estatal con la de las Comunidades Autónomas, el artículo 12 de la Ley crea el Consejo General de la Ciencia y la Tecnología, órgano al que le dedicaremos mayor atención en el apartado de la organización de la ciencia y la tecnología en las Comunidades Autónomas.

Finalmente es necesario mencionar a la Fundación Española para la Ciencia y la Tecnología (FECYT) que fue creada por acuerdo del Consejo de Ministros de 27 de abril de 2001 a iniciativa del Ministerio de Ciencia y Tecnología. Esta Fundación opera como una entidad sin ánimo de lucro y con autonomía funcional, con el objeto de prestar un servicio continuado y flexible al sistema español de ciencia-tecnología-empresa. Asimismo, contribuye a identificar oportunidades y necesidades, a la vez que propone formas de actuación a los agentes del sistema de investigación científica y de innovación tecnológica. En el Patronato de esta Fundación están representados los Ministerios de Ciencia y Tecnología, Educación, Cultura y Deporte, y Sanidad; también hay representantes de los OPIS, de las Universidades y de la CDTI.

\section{LA ADMINISTRACIÓN INSTRUMENTAL EN MATERIA DE CIENCIA Y TECNOLOGÍA: LOS ORGANISMOS PÚBLICOS DE INVESTIGACIÓN Y EL RÉGIMEN JURÍDICO DE SU PERSONAL}

Desde que en 1939 se crea el Consejo Superior de Investigaciones Científicas (CSIC), ha sido tradicional en nuestro país que el peso de la investigación se llevase a cabo mediante diferentes figuras organizativas de carácter público, fundamentalmente, organismos autónomos y,

nes privadas de investigación y centros tecnológicos. c) Siete representantes de empresas innovadoras. d) Dos representantes de las asociaciones empresariales que tengan, en el ámbito estatal, la representatividad prevista en la disposición adicional sexta del texto refundido de la Ley del Estatuto de los Trabajadores, aprobado por el Real Decreto Legislativo 1/1995, de 4 de marzo. e) Dos representantes de las organizaciones sindicales que, de acuerdo con la Ley Orgánica 11/1985, de 2 de agosto, de Libertad Sindical, ostenten en el ámbito estatal el carácter de más representativas. 5. Serán Consejeros natos del Consejo Asesor para la Ciencia y la Tecnología, por razón de su cargo: a) El Secretario de Estado de Infraestructuras del Ministerio de Fomento. b) El Secretario de Estado de Educación y Universidades del Ministerio de Educación, Cultura y Deporte. c) El Subsecretario de Economía. d) El Secretario general de Gestión y Cooperación Sanitaria del Ministerio de Sanidad y Consumo. e) El Secretario general de Pesca Marítima del Ministerio de Agricultura, Pesca y Alimentación. f) El Secretario general de Medio Ambiente del Ministerio de Medio Ambiente. g) El Director general de Investigación del Ministerio de Ciencia y Tecnología. h) El Director general de Política Tecnológica del Ministerio de Ciencia y Tecnología. i) El Director general del Centro para el Desarrollo Tecnológico Industrial». 
recientemente, entidades públicas empresariales. A la mayor parte de estos entes que conforman la que podríamos llamar la Administración instrumental en materia de ciencia y tecnología se les conoce como «organismos públicos de investigación» (OPIS).

\section{RÉGIMEN JURÍDICO COMÚN DE LOS ORGANISMOS PÚBLICOS DE INVESTIGACIÓN}

Como algo consustancial a toda Administración Instrumental, uno de los problemas más importantes que presenta es el de su heterogeneidad. Desde un punto de vista jurídico, cada uno de los múltiples OPIS que fueron creando los diferentes departamentos ministeriales tenían su propio régimen jurídico.

Para corregir en parte esta disfunción, el capítulo II de la Ley de la Ciencia trató de definir un marco común para el funcionamiento de algunos centros de investigación dependientes de la Administración del Estado. El artículo 13 de la Ley de la Ciencia, en su versión dada por la Ley 14/2000, de 29 de diciembre, señala que «El Consejo Superior de Investigaciones Científicas (CSIC), el Centro de Investigaciones Energéticas, Medioambientales y Tecnológicas (CIEMAT), el Instituto Geológico y Minero (IGME), el Instituto Nacional de Técnica Aeroespacial (INTA), el Instituto Nacional de Investigación y Tecnología Agraria y Alimentaria (INIA), el Instituto Español de Oceanografía (IEO) y el Instituto de Salud Carlos III, se regirán por la presente Ley, por su legislación específica y por la Ley 6/1997, de 14 de abril, de Organización y Funcionamiento de la Administración General del Estado».

La primera cuestión a resolver en este régimen jurídico común es lo referente a las funciones a cumplir por los Organismos públicos de investigación. En este sentido, el artículo 14 de la Ley las concreta en: a) Gestionar y ejecutar los Programas Nacionales y Sectoriales que les sean asignados en el Plan Nacional y, en su caso, los derivados de convenios firmados con Comunidades Autónomas al amparo de lo establecido en el artículo 15, así como desarrollar los programas de formación de investigadores que en dicho Plan les sean encomendados; b) contribuir a la definición de los objetivos del Plan Nacional y colaborar en las tareas de evaluación y seguimiento de los mismos; c) asesorar en materia de investigación científica e innovación tecnológica a los Organismos dependientes de la Administración del Estado o de las Comunidades Autónomas que lo soliciten; d) cualquier otra que les sea encomendada por la Administración competente. 
El artículo 16 de la Ley definió una estructura común de los órganos de gobierno de estos centros de investigación, que serían un presidente y un consejo rector presidido por aquél. La composición del Consejo Rector se establecerá reglamentariamente en función de las características específicas de cada Organismo. Por su parte, la Disposición Adicional $3^{a}$ obligaba al desarrollo de reglamentos de organización, funcionamiento y personal, deber que poco a poco se ha ido cumpliendo en el tiempo como posteriormente concretaré.

El artículo 19 de la Ley, en la versión dada mediante la Ley 24/2001, de 27 de diciembre, establece la posibilidad de que los organismos públicos de investigación puedan, previa autorización del Gobierno, crear o participar en el capital de sociedades mercantiles cuyo objeto sea la realización de alguna de las siguientes actividades: a) La investigación científica, el desarrollo o la innovación tecnológica; b) la explotación de patentes de invención y, en general, la cesión y explotación de los derechos de la propiedad industrial e intelectual; c) el uso y el aprovechamiento, industrial o comercial, de las innovaciones, de los conocimientos científicos y de los resultados obtenidos y desarrollados por el organismo; d) la prestación de servicios técnicos relacionados con los fines propios del organis$\mathrm{mo}^{18}$. Tendrán la consideración de aportaciones de los organismos públicos de investigación a la sociedad mercantil: las participaciones en el capital; la cesión de los derechos de la propiedad industrial e intelectual; y la cesión o el uso de las innovaciones, de los conocimientos científicos y de los resultados obtenidos o desarrollados por el propio organismo.

Para flexibilizar el régimen de la contratación de los organismos públicos de investigación, el artículo 19.2 en la versión dada con la Ley 14/2000, de 29 de diciembre, señala que «Los contratos de prestación de servicios de investigación que realicen los organismos a que se hace referencia en el apartado anterior, quedan exceptuados en el ámbito de aplicación del Real Decreto Legislativo 2/2000, de 16 de junio, por el que se aprueba el texto refundido de la Ley de Contratos de las Administraciones Públicas y se regirán por las normas de Derecho Civil y Mercantil que les sean de aplicación ${ }^{19}$.

Por su parte, el apartado $3^{\circ}$ de este mismo artículo 19 señala que los contratos que realicen tales Organismos relativos a obras de tecnología especialmente avanzada o cuya ejecución sea particularmente comple-

18 A título de ejemplo, el Centro de Investigaciones Energéticas, Medioambientales y Tecnológicas (CIEMAT), participa en un $80 \%$ en la Empresa Nacional de Residuos Radioactivos (ENRESA); en el 40\% del capital de ENUSA INDUSTRIAS AVANZADAS S.A. y en el 28\% de la Fundación CENER-CIEMAT.

19 Sobre la impugnación de un contrato celebrado por el CSIC ante la jurisdicción ordinaria, véase la Sentencia de la Audiencia Provincial de Madrid (Sección 10ª), de 31 de enero de 1998 (Ar 7123). 
ja se adjudicarán, en todo caso, por el procedimiento de concurso. La excepción a este criterio general se determina en el apartado $4^{\circ}$ de este mismo precepto ya que se establece que los OPIS podrán adquirir, por el sistema de adjudicación directa, previa autorización de su Consejo Rector, los bienes de equipo necesarios para el desarrollo de las tareas de investigación.

Los OPIS son, en su mayoría, simples ejecutores de investigación. Sin embargo, en dos casos mantienen funciones de gestión de fondos de investigación de naturaleza competitiva que están incluidos en sus presupuestos. El ISCIII o Instituto de Salud «Carlos III ${ }^{20}$ gestiona desde 1997, el Fondo de Investigaciones Sanitarias (FIS), que representa del orden de un tercio del presupuesto total y que se destina a financiar investigación competitiva en biomedicina y salud, especialmente en hospitales. El INIA o Instituto Nacional de Investigación y Tecnología Agraria y Alimentaria ${ }^{21}$ ha venido gestionando tradicionalmente un fondo de investigación agraria, destinado esencialmente a los centros del denominado «sistema INIA», centros transferidos u organizados por las Comunidades Autónomas y que también representa un tercio de los presupuestos del INIA.

Desde un punto de vista organizativo, una de las cuestiones más interesantes y de las que depende en gran medida el funcionamiento de los OPIS es el grado de relación y dependencia con respecto a los Ministerios en los que se incluyen. Las posibles situaciones que pueden darse en la práctica atendiendo a la independencia, sobre todo en lo que a la captación de recursos se refiere, han sido muy bien analizadas por SANZ MENÉNDEZ y CRUZ CASTRO ${ }^{22}$. Para estos autores, la carencia, de forma simultánea, de autonomía organizativa e individual en algunos OPIS nos presenta una situación de fuerte dependencia del centro tanto a nivel interno como externo. La dependencia completa crea un modelo de «respuesta pasiva» basado en la aceptación de los cambios en el entorno de modo más o menos conformista, esperando que el Ministerio de tutela o la Administración favorezca la solución de los problemas que el centro tiene.

En el caso de que un centro disponga de autonomía organizativa respecto al sistema político, pero cuyos investigadores tienen una auto-

${ }^{20}$ Este instituto fue creado en 1986 bajo la dependencia del Ministerio de Sanidad y Consumo. Tiene como áreas científicas y tecnológicas de competencia la Biomedicina y la salud humana y contaba en el año 2000 con un personal de 839 miembros.

21 El INIA fue creado en 1971 bajo la dependencia, hasta abril de 2000 en que se integra en Ciencia y Tecnología, del Ministerio de Agricultura, Pesca y Alimentación y cuenta como Áreas científicas y tecnológicas de competencia con la Agricultura, ganadería, forestal y alimentación. Contaba en el año 2000 con un personal de 530 miembros.

22 L. SANZ MENÉNDEZ y L. CRUZ CASTRO, «Autonomía y adaptación organizativa: los centros de investigación ante los cambios del entorno», Reis, no 95/2001, pp. 45 y ss. 
nomía limitada en el seno de la organización, bien porque carecen de incentivos individuales para comportarse de forma autónoma y reforzar sus grados de independencia por el procedimiento de la búsqueda de fondos, o bien porque dependen de los recursos organizativos para llevar a cabo su actividad investigadora y los fondos que pudiesen obtener no cubrirían en ningún caso el coste de los equipos necesarios. El tipo de respuesta de los centros de investigación que están en esta situación será fundamentalmente el resultado de las estrategias y acciones de los directivos, cuyo control sobre los recursos tangibles de la organización fortalece su posición de autoridad; la respuesta de adaptación será activa, pero en este caso de carácter colectivo, ya que la búsqueda de financiación externa toma aquí la forma de función directiva.

Por último, si existe autonomía de la organización respecto del sistema político y, además, o bien se han desarrollado sistemas de incentivos individuales que promueven la autonomía de los investigadores respecto de la organización, o bien éstos no dependen de los recursos organizativos para investigar, podemos predecir que, a partir de estas dos dimensiones de la autonomía, la respuesta esperable respecto de los cambios del entorno será la adaptación activa basada en las estrategias individuales.

En cuanto al régimen presupuestario de los OPIS, la mayor parte de ellos se financian directamente de los Presupuestos Generales del Estado aunque en los últimos años han conseguido financiar una parte importante de su actividad mediante recursos propios, es decir, los procedentes de sus operaciones comerciales. De media podría decirse que esta autofinanciación está en torno al 20\% (38\% el CSIC como el que más y $6 \%$ el que menos ISC III) ${ }^{23}$.

\section{LA ADMINISTRACIÓN INSTRUMENTAL ESPAÑOLA DE CIENCIA Y TECNOLOGÍA}

La adaptación de los OPIS a la LOFAGE ${ }^{24}$ supuso su conversión en Organismos Autónomos de la Administración del Estado con las peculiaridades que demanda la tarea investigadora. Adaptación que tuvo lugar mediante la Ley 50/1998, de 30 de diciembre. En esta norma se establece que el Gobierno promulgaría por Decreto el Estatuto de cada uno de los OPIS. No se trata de elaborar «un estatuto del personal» cuya formulación deberá aprobarse tras la aprobación del Estatuto de la

23 J. LÓPEZ FACAL y D. REPRESA SÁNCHEZ, «Los organismos públicos de investigación» (OPIS), en Arbor CLX, 629 (Mayo 1998), pp. 1-33.

24 Ley 6/1997, de 14 de abril, de Organización y Funcionamiento de la Administración General del Estado. 
DA-2003, núms. 265-266. ESTANISLAO ARANA GARCÍA. Organización administrativa de la ciencia...

Función Pública, sino de elaborar una norma que, partiendo de la legislación general aplicable, suponga un avance en la definición del marco específico de organización y funcionamiento de cada Organismo derivado de las especialidades requeridas por las actividades que desarrolla.

En este apartado, evidentemente, no podemos analizar exhaustivamente el régimen jurídico de cada uno de los Organismos de Investigación que existen en España. Tan sólo vamos a presentar las distintas figuras organizativas públicas que se dedican a la investigación, indicando cuáles son sus objetivos y remitiendo a las normas concretas que desarrollan su régimen jurídico.

Como veremos, la mayor parte de los organismos públicos de investigación dependen en la actualidad del Ministerio de Ciencia y Tecnología. No obstante, existen, además, otros centros públicos dedicados a la investigación que jurídicamente no se consideran organismos públicos de investigación y, por otra parte, existen otros organismos o centros públicos de investigación que no se insertan organizativamente dentro de este Ministerio.

El RD 696/2000, de 12 de mayo, que establece la estructura orgánica básica del Ministerio de Ciencia y Tecnología señala que están adscritas al Ministerio de Ciencia y Tecnología, a través de la Secretaría de Estado de Política Científica y Tecnológica, las siguientes entidades públicas empresariales: a) El Instituto para la Diversificación y Ahorro de la Energía (IDAE) ${ }^{25}$; b) El Centro para el Desarrollo Tecnológico Industrial $(\mathrm{CDTI})^{26}$; c) La Gerencia del Sector Naval.

En un segundo nivel, el Real Decreto señala que, simplemente, se relacionará administrativamente con el Departamento, a través de la Secretaría de Estado de Política Científica y Tecnológica, el Instituto de Astrofísica de Canarias, regulado por la Ley 13/1986, de 14 de abril, y por el Real Decreto 795/1989, de 23 de junio.

Por lo que respecta a los OPIS estrictamente considerados, se establece que están adscritos al Ministerio de Ciencia y Tecnología, a través de la Secretaría General de Política Científica, los siguientes:

a) Consejo Superior de Investigaciones Científicas (CSIC), bajo cuya dirección ejecutará las tareas de investigación científica y de coordinación de tal carácter que se deriven de las directrices que establezca el Gobierno en materia de política científica y de desarrollo tecnológico, en el ámbito de sus competencias. El CSIC en términos de presupuesto y de personal representa aproximadamente el $50 \%$ de todos los organis-

25 Regulado mediante el RD 802/1986, de 11 de abril, modificado por el RD 252/1997, de 21 de febrero.

26 Regulado mediante el RD 1406/1986, de 6 de junio, modificado por los Reales Decretos 2100/1998, de 25 de septiembre y por el 1270/1988, de 28 de octubre. 
mos públicos de investigación, tiene carácter plurisectorial. El Consejo tiene como fin primordial promover y realizar investigación científica y técnica dentro del marco y al servicio de la política científica y tecnológica del país, con objeto de impulsar y contribuir a su desarrollo económico, social y cultural. Su Estatuto ha sido aprobado mediante el RD 1945/2000, de 1 de diciembre.

b) Centro de Investigaciones Energéticas, Medioambientales y Tecnológicas (CIEMAT), organismo autónomo que tiene por finalidad la promoción y desarrollo de actividades de investigación básica, investigación aplicada, innovación y desarrollo tecnológicos, con especial atención al ámbito energético y medioambiental, contribuyendo al desarrollo de procesos industriales más eficientes, con las restricciones inherentes a la preservación de la salud humana y a la conservación del medio ambiente. Su Estatuto se aprueba mediante el RD 1952/2000, de 1 de diciembre.

c) Instituto Nacional de Investigación y Tecnología Agraria y Alimentaría (INIA), que tiene como objetivos la programación, coordinación, asignación de recursos, seguimiento y evaluación de actividades de investigación científica y técnica, así como la ejecución de las funciones de investigación y desarrollo tecnológico, incluyendo las de transferencia tecnológica en materia agraria y alimentaria y cuyo Estatuto ha sido aprobado por el RD 1951/2000, de 1 de diciembre.

d) Instituto Español de Oceanografía (IEO), que tiene como finalidad el estudio de la mar y sus recursos y cuyo Estatuto ha sido aprobado mediante el RD 1950/2000, de 1 de diciembre.

e) Instituto Tecnológico Geominero Español (ITGE), que tiene como misión proporcionar a la Administración del Estado o de las Comunidades Autónomas que lo soliciten, y a la sociedad en general, el conocimiento y la información precisa en relación con las ciencias y tecnologías de la tierra para cualquier actuación sobre el territorio y cuyo Estatuto ha sido aprobado mediante el RD 1953/2000, de 1 de diciembre.

Existen otros organismos de investigación o relacionados con la investigación que se adscriben a diferentes Ministerios, entre ellos, destacar los siguientes:

a) El Instituto Nacional de Técnica Aeroespacial «Esteban Terradas», antiguo Instituto Nacional de Técnica Aeroespacial, es un organismo público de investigación pero ya no adscrito al Ministerio de Ciencia. Su Estatuto se aprueba mediante el RD 88/2001, de 2 de febrero, que establece que se trata de un organismo público de investigación de acuerdo con lo dispuesto en la Ley 13/1986, de 14 de abril, Organismo autónomo, adscrito al Ministerio de Defensa, a través de la Secretaría de Estado de Defensa, de los previstos en el artículo 43.1 a) de la LO- 
DA-2003, núms. 265-266. ESTANISLAO ARANA GARCÍA. Organización administrativa de la ciencia...

FAGE, especializado en la investigación y el desarrollo tecnológico aeroespacial, que actuará en el marco de las prioridades señaladas por el Ministerio de Defensa, y dentro de las directrices de investigación y desarrollo determinadas por el citado Departamento, con el fin de mantener una acción unitaria en el ámbito de las tecnologías de aplicación de la Defensa.

b) La Comisión Nacional de Astronomía que es un órgano colegiado de la Administración General del Estado dependiente de los Ministerios de Fomento y de Ciencia y Tecnología, que tiene como finalidades el impulso y coordinación de los programas astronómicos nacionales, el asesoramiento a la Administración General del Estado en materia de astronomía y astrofísica y la representación de España en la Unión Astronómica Internacional, desarrollando su misión de acuerdo con las directrices que establezca la Comisión Interministerial de Ciencia y Tecnología 27 .

c) El Instituto de Salud Carlos III cuyo estatuto se aprueba mediante el RD 375/2001, de 6 de abril. El Instituto de Salud «Carlos III» es un Organismo público de investigación con carácter de Organismo autónomo de los previstos en el artículo 43.1 a) de la Ley 6/1997, de 14 de abril, de Organización y Funcionamiento de la Administración General del Estado, adscrito al Ministerio de Sanidad y Consumo, a través de la Secretaría General de Gestión y Cooperación Sanitaria, cuya finalidad es el apoyo científico-técnico del Ministerio de Sanidad y Consumo y de los distintos Servicios de Salud de las Comunidades Autónomas y la colaboración, en el ámbito de sus funciones, con otras Administraciones públicas.

d) El Centro de Investigaciones Sociológicas que es un organismo autónomo adscrito al Ministerio de Presidencia y cuya organización se regula mediante el RD 1214/1997, de 18 de julio, tiene como funciones principales a cumplir: a) la programación, diseño y realización de estudios que contribuyan al conocimiento científico de la sociedad española, principalmente mediante la ejecución de las encuestas que sean necesarias para llevar a cabo dichos estudios; b) la programación, diseño y realización de estudios que contribuyan al conocimiento científico de la realidad social de las diferentes Comunidades Autónomas, cuando proceda, mediante la suscripción por el Centro, de los oportunos convenios de cooperación con las mismas; c) la realización de estudios que proporcionen diagnósticos sobre situaciones y asuntos sociales y sirvan de orientación a los poderes públicos en sus iniciativas normativas y ejecutivas; d) la creación y mantenimiento de bases de datos en las

27 Su régimen jurídico específico es el establecido mediante el RD 587/1989, de 12 de mayo, modificado por el RD 663/2001, de 22 de junio. 
materias de su competencia; e) el desarrollo de trabajos de documentación y la difusión de los resultados de la actividad científica del organismo, así como de otros estudios de naturaleza académica que contribuyan al conocimiento científico de la sociedad española; f) la promoción y estímulo de la investigación social aplicada, mediante la organización de cursos y seminarios, la convocatoria de becas, ayudas y premios, y la participación en programas de formación de técnicos y especialistas en la materia; g) el fomento de la colaboración científica con centros universitarios y de investigación para la realización de proyectos de investigación conjuntos, para la formación de investigadores en ciencias sociales, para la participación en reuniones y congresos, tanto a nivel nacional como internacional, y para la realización de planes de intercambio y cooperación con entidades españolas y extranjeras especializadas.

e) El Centro de Estudios Jurídicos de la Administración de Justicia, dependiente del Ministerio de Justicia y creado por la Ley Orgánica 9/2000, de 22 de diciembre

f) El Centro de Estudios Políticos y Constitucionales adscrito al Ministerio de la Presidencia y regulado por el Real Decreto 1269/1997 de 24 de julio, es un Organismo autónomo de los previstos en el artículo 43.1.a) de la Ley 6/1997, de 14 de abril, de Organización y Funcionamiento de la Administración General del Estado, con personalidad jurídica y patrimonio propios, cuya finalidad es el estudio y la investigación de los sistemas sociales, políticos, constitucionales y administrativos, manteniendo a tales efectos las oportunas relaciones con las instituciones propias de los países iberoamericanos.

g) El Instituto Hidrográfico de la Marina adscrito al Ministerio de Defensa y que persigue como objetivo la obtención de la información náutica necesaria y posterior suministro de la misma al navegante y Fuerzas Navales. Su regulación está constituida por las ordenes de 1 de abril de 1989 y de 29 de abril de 1982.

h) El Real Instituto y Observatorio de la Armada en San Fernando también dependiente del Ministerio de Defensa definido como Centro científico del Estado Mayor de la Armada que a su misión específica como Observatorio Astronómico y Geofísico une la de investigación en aquellos campos de la ciencia físico-matemática que se juzguen de interés para la Marina, así como la de proporcionar formación científica superior al personal que lo precise. Se regula por las Órdenes de 25 de abril de 1979 y de 1 de octubre de 1987.

i) El Instituto Nacional de Seguridad e Higiene en el Trabajo adscrito al Ministerio de Trabajo y Asuntos Sociales y que le corresponde la gestión, asesoramiento y control de las acciones técnico-preventivas dirigidas a la disminución de los riesgos laborales, accidentes de trabajo y enfermedades profesionales y que se encuentra regulado, fundamen- 
talmente, por el Real Decreto 577/1982, de 17 de marzo y por la Orden de 25 de enero de 1985.

Igualmente, pueden citarse dos institutos con rango de Direcciones Generales pero con un importante papel en el ámbito de la investigación, me refiero al Instituto Nacional de Meteorología y al Instituto Geográfico Nacional.

Se observa toda una variada red de organismos públicos de investigación que exigen la necesidad de garantizar la coordinación de todos ellos. A tal efecto el RD 547/1997, de 18 de abril, modificado por el 560/2001, de 25 de mayo, crea el Comité de Coordinación Funcional de los Organismos Autónomos de Investigación y Experimentación que trata de evitar duplicidades en las actividades de los mismos, y de asegurar un óptimo aprovechamiento de los recursos humanos, materiales y económicos puestos a disposición de la investigación científica y la experimentación en el ámbito de la Administración General del Estado.

\section{RÉGIMEN JURÍDICO DEL PERSONAL DE LOS OPIS}

Para completar el estudio de los organismos públicos de investigación me referiré ahora al régimen jurídico de su personal. Atendiendo a su estructura y distribución podemos decir que según los datos que disponemos hasta 1998 el personal de los OPIS está compuesto por funcionarios (un 47,8\%), laborales $(32,8 \%$ ) y otro personal $(19,3 \%)$, en el que se incluyen becarios, contratados con cargo a proyectos, doctores vinculados, etc $^{28}$.

El régimen jurídico de cada una de estas modalidades de personal es el establecido con carácter general para todo el personal al servicio de las Administraciones públicas con algunas especialidades, algunas de las cuales vamos a comentar a continuación.

En primer lugar, destacar la intención del Ordenamiento jurídico de facilitar e incentivar la movilidad del personal investigador de los OPIS. En este sentido, la disposición adicional cuarta en su redacción dada por la Ley 14/2000, de 29 de diciembre, señala que el Gobierno, a iniciativa de los Departamentos ministeriales a los que estén adscritos los Organismos públicos de investigación a los que se refiere esta Ley, y a propuesta del Ministerio de Administraciones Públicas, dictará las normas necesarias para facilitar e incentivar la movilidad del personal investigador al servicio de los organismos públicos de investigación dependientes de la Administración del Estado. Asimismo, y de acuerdo

28 J. LÓPEZ FACAL y F. REPRESA SÁNCHEZ, «Los organismos públicos...», cit. anteriormente p. 8 . 
DA-2003, núms. 265-266. ESTANISLAO ARANA GARCÍA. Organización administrativa de la ciencia...

con las Comunidades Autónomas y las Corporaciones locales, en su caso, se establecerán medidas para facilitar e incentivar la movilidad de este personal entre las respectivas Administraciones públicas.

En segundo lugar, respecto del personal laboral al servicio de los OPIS, señalar que el artículo 17 de la Ley de la Ciencia en redacción dada por la Ley 12/2001, de 9 de julio, señala que los organismos públicos de investigación podrán celebrar, con cargo a sus presupuestos administrativos o comerciales, y de acuerdo con lo que establezcan sus respectivos Estatutos, los siguientes contratos laborales: a) Contratos para la realización de un proyecto específico de investigación. Estos contratos se regirán por lo dispuesto en el artículo 15.1.a) del Estatuto de los Trabajadores, con las siguientes particularidades: podrán formalizarse con personal investigador, o personal científico o técnico y la actividad desarrollada por éstos será evaluada anualmente, pudiendo ser resuelto el contrato en el supuesto de no superarse favorablemente dicha evaluación; b) contratos para la incorporación de investigadores al sistema español de ciencia y tecnología. Estos contratos se regirán por el artículo 11.1 del Estatuto de los Trabajadores, con las siguientes particularidades: sólo podrán concertarse con quienes estuviesen en posesión del título de Doctor, sin que sea de aplicación el límite de cuatro años a que se refiere el precepto antes citado. El trabajo a desarrollar consistirá en la realización de actividades, programas o proyectos de investigación que permitan ampliar, perfeccionar o completar la experiencia científica de los interesados. La actividad desarrollada por los investigadores será evaluada, al menos, cada dos años, pudiendo ser resuelto el contrato en el supuesto de no superarse favorablemente dicha evaluación. La duración del contrato no podrá ser inferior a un año, ni exceder de cinco años. Cuando el contrato se hubiese concertado por una duración inferior a cinco años podrá prorrogarse sucesivamente sin que, en ningún caso, las prórrogas puedan tener una duración inferior al año. Ningún investigador podrá ser contratado, en el mismo o distinto organismo y con arreglo a esta modalidad, por un tiempo superior a cinco años. La retribución de estos investigadores no podrá ser inferior a la que corresponda al personal investigador que realice idénticas o análogas actividades ${ }^{29}$.

Los organismos públicos y las instituciones sin ánimo de lucro que realicen actividades de investigación y desarrollo tecnológico, a los que se refiere el artículo 11 de esta Ley, podrán contratar personal investiga-

29 Acerca de la duración de estos contratos laborales antes de que se produjera la modificación del art. 17 b) en el 2001, pueden verse las Sentencias del Tribunal Superior de Justicia de Madrid, Sala de lo Social, de 21 de marzo de 2001 (Ar 1756); 9 de febrero de 2001 ( $\mathrm{Ar}$ 1250); 2 de febrero de 2001 ( $\operatorname{Ar} 1247) ; 19$ de enero de 2001 (Ar 547); 14 de diciembre de 2001 (Ar 716) y 21 de septiembre (Ar 4139). 
dor, o personal científico o técnico, con arreglo a lo dispuesto en el apartado anterior. Las Universidades públicas únicamente podrán celebrar los contratos a que se refiere el párrafo anterior cuando sean beneficiarias de ayudas o subvenciones públicas para la contratación temporal de personal investigador, científico o técnico, para el desarrollo de nuevos programas o proyectos singulares de investigación que no puedan llevar a cabo con personal propio ${ }^{30}$.

Por lo que al personal funcionario se refiere, simplemente, significar dos cuestiones:

1) Con el objetivo de facilitar la posibilidad de incentivar al personal de los organismos públicos de investigación el artículo 18 de la Ley de la Ciencia se modifica mediante la Ley 50/1998, de 30 de diciembre. Así, además de preverse la posibilidad del complemento de productividad, se añade la referencia a las gratificaciones por servicios extraordinarios a que se refiere el artículo 23.3 c) y d) de la Ley 30/1984, de 2 de agosto, así como a la de cualquier otro incentivo al rendimiento incluido en el artículo 15 de la actual clasificación económica de los gastos. En estos casos, se requerirá informe favorable del Ministerio de Economía y Hacienda para la autorización de la correspondiente generación de crédito.

2) El artículo 19 de la Ley de la Ciencia modificado, como ya dijimos, por la Ley 24/2001 para posibilitar la creación o participación por los OPIS en el capital de sociedades mercantiles, en su número $2^{\circ}$ señala que los funcionarios de dichos organismos que pasen a prestar servicios en las citadas sociedades mercantiles podrán solicitar la concesión de licencias para desarrollar tareas directamente relacionadas con la actividad científica o técnica que realicen en el Organismo. Dichas licencias se concederán sin retribución alguna, por un plazo máximo de 4 años y con derecho a conservar el puesto de trabajo. La concesión de estas licencias se subordinará a las necesidades del servicio, al interés para el organismo de los trabajos científicos y técnicos a desarrollar y se ajustará al procedimiento, condiciones y requisitos que se establezcan mediante Orden del Ministerio de Ciencia y Tecnología, previo informe favorable del Ministerio de Administraciones Públicas.

Por lo que se refiere a las diferentes categorías de investigadores en los OPIS, el artículo 35 de la Ley 14/2000, de 29 de diciembre, establece una figura homogénea de investigador para todos los OPIS a la que se

${ }^{30}$ Por lo que a este personal laboral respecta señalar que la Resolución de la Dirección general de Trabajo de 1 de diciembre de 1997 publicada en el BOE el 18 de diciembre de 1997, aprueba el Convenio Colectivo del Personal Laboral del CSIC. Por su parte, la Resolución de 30 de septiembre de 1997 publicada en el BOE de 14 de noviembre del mismo año, aprueba la Relación de Puestos de Trabajo del CSIC. 
pueden acoger todos los funcionarios de estos organismos que a la entrada en vigor de la norma reúnan una serie de requisitos. Con esta intención, se procede a la creación de las Escalas de los Organismos Públicos de Investigación en el Ministerio de Ciencia y Tecnología que queda adscrita a tal Departamento, y clasificada en el grupo A de la Ley 30/1984, de 2 de agosto, de Medidas para la Reforma de la Función Pública $^{31}$. Fundamentalmente se crean dos escalas diferentes: investigadores titulares y técnicos superiores especialistas.

No obstante, a nivel de noticia de prensa ${ }^{32}$ se anuncia que en la Ley de Acompañamiento a los Presupuestos para 2003 se pretende crear escalas homogéneas para los investigadores de todos los organismos públicos de investigación. Medida que persigue definir la carrera profesional de investigador y favorecer la movilidad de científicos entre los organismos públicos de investigación dependientes de Ciencia y Tecnología.

\section{CIENCIA Y TECNOLOGÍA Y COMUNIDADES AUTÓNOMAS}

\section{LA DISTRIBUCIÓN DE COMPETENCIAS ENTRE EL ESTADO Y LAS COMUNIDADES AUTÓNOMAS EN CIENCIA Y TECNOLOGÍA}

Hasta ahora me he referido exclusivamente a la organización de la Ciencia y la Tecnología en el ámbito de la Administración Central del Estado. Para tener una visión general de la organización administrativa de la Ciencia y la Tecnología en España, falta por aludir, brevemente, a la forma de organizar esta parcela de actividad pública en las Comunidades Autónomas.

El artículo 149.1.15 de la CE atribuye a la Administración del Estado la competencia sobre el fomento y la coordinación general de la investigación científica y técnica. Por su parte, el artículo 148.1.17 establece que las Comunidades Autónomas podrán asumir competencias para el fomento de la investigación. Partiendo de esta situación significar que prácticamente todos los Estatutos de Autonomía han previsto la reserva de competencias de Investigación y Desarrollo.

La Ley 13/1986, consciente de esta multiplicidad de entes territoriales con competencias en una misma materia, trató de establecer mecanismos para la coordinación de toda esta estructura estatal. Así, se

31 El Real Decreto 868/2001, de 20 de julio, desarrolla esta norma estableciendo los criterios concretos para la integración en las Escalas de Investigadores Titulares de los Organismos Públicos de Investigación y de Técnicos Superiores Especialistas de los Organismos Públicos de Investigación.

32 Diario $A B C$ de 6 de julio de 2002, p. 30. 
previó la creación de un Consejo General de la Ciencia y la Tecnología, órgano que será la base de la coordinación con las CCAA y compuesto por representantes de las CCAA, uno por cada una, y por miembros designados por el gobierno de los de la CICYT, en un número no superior a los de las CCAA, pero con igual número de votos que los de éstas.

Según el artículo 12 de la Ley, a este órgano le correspondía «promover la coordinación general de la investigación científica y técnica» dotándose para ello de una serie de funciones descritas en el apartado $3^{\circ}$ de este precepto.

Además de este órgano, el artículo 15 de la Ley 13/1986, en su versión dada por la Ley 24/2001, de 27 de diciembre, se refiere expresamente a la posibilidad de que los organismos públicos de investigación celebren convenios de colaboración con las Comunidades Autónomas ${ }^{33}$.

Sin embargo, el sistema creado por la Ley de la Ciencia no funcionó como estaba previsto, la coordinación que se impuso en la práctica correspondió a un simple intercambio de información, lugar de encuentro y, como ocurrió a propuesta de la Generalitat catalana y valenciana, la inclusión de programas regionales en la estructura del Plan Nacional de I+D. Ante esta situación la Generalitat y el Parlamento de Cataluña plantearon sendos recursos de inconstitucionalidad contra la Ley 13/1986, sobre todo por lo que se refiere a su concepto de «coordinación general».

Para Cataluña la Ley no establecía una verdadera coordinación general de toda la investigación científica española. En primer lugar porque quedaba al margen de su consideración la actividad investigadora

33 «Los organismos públicos de investigación podrán celebrar convenios de colaboración con las Comunidades Autónomas para la realización de las siguientes actividades: a) Proyectos de investigación científica, desarrollo e innovación tecnológica. b) Transferencia de conocimientos y de resultados científicos. c) Creación, gestión o financiación de centros o unidades de investigación. d) Formación de especialistas. e) Uso compartido de inmuebles, de instalaciones y de medios materiales para el desarrollo de actividades científicas relacionadas con los fines propios del organismo. f) Asignación temporal de personal para la realización de actividades científicas o técnicas, sin que ello suponga alteración del régimen jurídico aplicable al mismo. Deberá darse cuenta de los referidos convenios de colaboración a la Comisión Interministerial de Ciencia y Tecnología. 2. Asimismo, los organismos públicos de investigación podrán suscribir convenios de colaboración con universidades, con fundaciones o con instituciones sin ánimo de lucro, tanto nacionales como extranjeras, para la ejecución y desarrollo de las actividades a que se refiere el apartado anterior. 3. Los organismos públicos de investigación también podrán suscribir convenios de colaboración con las empresas, bien sean públicas o privadas, que realicen actividades de investigación, desarrollo e innovación tecnológica, para la realización de las actuaciones a que se refieren las letras a), b), c) y d) del apartado 1 del presente artículo. A efectos de determinar las contraprestaciones de las empresas, las actividades o servicios que realicen los organismos públicos de investigación serán valorados a precios de mercado. El objeto de estos convenios no podrá ser ninguno de los comprendidos en los contratos regulados en el Real Decreto Legislativo 2/2000, de 16 de junio, por el que se aprueba el Texto Refundido de la Ley de Contratos de las Administraciones Públicas o en normas administrativas especiales». 
que desarrollaban las CCAA; en segundo término porque el Consejo General que la Ley creó tenía solamente funciones consultivas y, por último, porque las CCAA no tenían participación alguna en el verdadero órgano decisor que era la CICYT. Se trataba, por todo ello, de un modelo de ordenación imperativa, ya que ignoraba las actividades y el papel de las CCAA en la investigación científica y técnica.

La segunda parte del recurso se refería al reparto competencial, en relación a lo cual la Generalitat y el Parlamento de Cataluña argumentaban que el Estado no había reservado ninguna competencia legislativa básica y su Estatuto le reconocía competencias plenas para la acción en materia de investigación científica y técnica y su política sólo estaba sometida a la coordinación general del Estado.

En tercer lugar se argumentaba que, al atribuirse la realización del Plan Nacional de I+D a los órganos del Estado, se impedía la transferencia a las CCAA de los órganos encargados de la ejecución de la investigación. Al otorgarse las tareas de fomento a los organismos públicos de investigación aparecían como no transferibles y si la Generalitat quisiera ejercer sus competencias plenas se produciría una duplicación entre las actividades de los centros estatales y los centros autonómicos, lo que iría en contra del espíritu de la coordinación.

La STC 90/1992, de 11 de junio de 1992, desestimó el recurso. El TC reconoció que el Estado, en el ejercicio de sus competencias y potestades relacionadas con la tarea de fomento, puede crear los organismos que considerase necesarios, tales como la CICY'T. Además, se afirmó que el titular de la competencia de coordinación es quien la ejerce y, por tanto, puede poner los medios, cauces y fórmulas para integrar las acciones. Por último, para el TC el que la ley se refiera solamente a los organismos de titularidad estatal, no interfería las competencias propias de la Generalitat.

A pesar de estos recursos de inconstitucionalidad, a partir de 1989, quedaron incorporados como «programas de Comunidades Autónomas» dos, propuestos desde Cataluña y Valencia. La Ley y la práctica apuntaban a que la forma de participación autonómica era la presentación de programas de comunidades autónomas y su aprobación y cofinanciación por el Estado. La viabilidad práctica de este sistema de coordinación se basaba en el supuesto de una mayor disponibilidad de fondos financieros para el fomento por parte de la Administración del Estado frente a las CCAA. Sin embargo, el presupuesto nacional para $\mathrm{I}+\mathrm{D}$ se estancó o, incluso, se redujo mientras las CCAA lanzaron ambiciosos planes regionales de I+D o de Innovación en Andalucía, Ma-

34 L. SANZ MENÉndeZ, Estado, ciencia..., cit. anteriormente, p. 298. 
DA-2003, núms. 265-266. ESTANISLAO ARANA GARCÍA. Organización administrativa de la ciencia...

drid, Galicia. etc., muchos de ellos aprobados en el marco de leyes regionales de fomento de la $\mathrm{I}+\mathrm{D}^{34}$.

\section{ORGANIZACIÓN Y POLÍTICA LEGISLATIVA EN MATERIA DE CIENCIA Y TECNOLOGÍA EN LAS DIFERENTES COMUNIDADES AUTÓNOMAS}

Son ya bastantes las Comunidades que han hecho ejercicio de sus competencias en materia de ciencia y tecnología, sobre todo recientemente. Daré a continuación un repaso a las normas más importantes dictadas por las diferentes Comunidades Autónomas así como a las organizaciones y organismos encargados de ejecutarlas ${ }^{35}$.

La Comunidad Valenciana ha aprobado la Ley 7/1998, de 8 de enero, de Fomento y Coordinación de la Investigación Científica y del Desarrollo Tecnológico. En el Capítulo I de la ley se definen las finalidades de la misma en cuanto al fomento de la investigación científica y desarrollo tecnológico, la mejora del sistema productivo de la Comunidad Valenciana, y la coordinación efectiva de todos los recursos dedicados a la política científica valenciana. El Capítulo II está destinado a los instrumentos de planificación, los Planes Valencianos de Investigación Científica y Desarrollo Tecnológico (PVID), como elementos sustitutivos del actual Plan Valenciano de Ciencia y Tecnología, que se dotan de mayor alcance científico y presupuestario y se articulan a través de programas de desarrollo temporal. El Capítulo III crea como órganos de gestión de los PVID a la Comisión Gestora Interdepartamental y su Comisión Permanente, a la Secretaría del Plan y al Consejo Asesor de Ciencia y Tecnología. Por último, existe un capítulo dedicado a los organismos públicos de investigación como elementos dinamizadores de la ciencia y la tecnología, y define un régimen jurídico común a todos ellos. En esta dirección se crea el Organismo Público Valenciano de Investigación (OPVI) como un organismo público de carácter multisectorial y pluridisciplinar al servicio de la política científica y tecnológica de la Comunidad Valenciana ${ }^{36}$.

En Galicia la Ley 12/1993, de 6 de agosto, de Fomento de la investigación y del desarrollo tecnológico, para llevar adelante sus principios crea: el Plan gallego de investigación y desarrollo tecnológico, que es el conjunto de programas coordinados, presupuestados, priorizados y financiados que responden a la política científica y tecnológica de la Co-

35 Sobre esta cuestión puede verse M. CUETO PÉREz, Régimen jurídico..., cit. anteriormente, pp. 161 y ss.

36 El Decreto 98/2001, de 16 de junio, por el que se regula los órganos de gestión de los Planes Valencianos de Investigación Científica, Desarrollo Tecnológico e Innovación. 
DA-2003, núms. 265-266. ESTANISLAO ARANA GARCÍA. Organización administrativa de la ciencia...

Organización administrativa de la ciencia...

munidad Autónoma; la Comisión Interdepartamental de Ciencia y Tecnología de Galicia y la Secretaría General del Plan gallego de investigación y desarrollo tecnológico, ambos entes elaboran y ejecutan el plan y emiten el informe al Parlamento sobre su desarrollo; el Consejo Asesor de Investigación y Desarrollo Tecnológico, que es el vínculo efectivo entre los agentes sociales, la comunidad científica y los responsables de la política científica y tecnológica de la Comunidad Autónoma; los centros tecnológicos, como organismos ejecutores de $\mathrm{I}+\mathrm{D}$ en ámbitos de interés estratégicos para el desarrollo productivo de Galicia. Asimismo, la de fomento de investigación y de desarrollo tecnológico de Galicia establece para conseguir sus fines: la coordinación de las actividades de investigación y desarrollo tecnológico de los diferentes departamentos; la concertación con programas estatales, autonómicos y comunitarios de I+D; la evaluación, seguimiento y financiación del plan; la armonización de los programas que han de ejecutarse en el plan; la incorporación de los sectores productivos en las tareas de planificación y ejecución de las actividades de investigación y de desarrollo tecnológico ${ }^{37}$.

La Comunidad Autónoma de Madrid aprobó la Ley 5/1998, de 7 de mayo, de Fomento de la Investigación Científica y la Innovación Tecnológica. Ley que tiene tres grandes objetivos a cumplir, en primer lugar, apoyar la investigación de calidad. En segundo lugar, poner en contacto la investigación de calidad con distintas administraciones y los agentes económicos y sociales con capacidad de innovación. Una tercera línea de actuación, necesaria en los momentos actuales, consistiría en incorporar a la región de Madrid a los ejes de la política de la Unión Europea a través de los proyectos regionales de innovación y la participación en las redes europeas. En un plano organizativo, la Comunidad de Madrid configura como órganos responsables de esta política, a la Dirección General de Investigación, la Comisión Interdepartamental y el Consejo de Ciencia y Tecnología ${ }^{38}$.

La Comunidad Autónoma de La Rioja aprobó la Ley 3/1998, de 16 de marzo, de Fomento, Coordinación y Desarrollo de la Investigación y el Desarrollo Tecnológico. En el plano organizativo esta Ley crea: la

37 Esta Ley ha sido desarrollada, entre otras, por las siguientes normas reglamentarias: Decreto 18/2002, de 1 de febrero de Composición de la Comisión Interdepartamental de Ciencia y Tecnología; el Decreto 14/1998, de 15 de enero, que establece el Consejo Asesor de Investigación y Desarrollo Tecnológico y el Decreto 142/2001, de 5 de julio, que regula el Registro de Centros e Instituciones de Investigación e Investigadores.

38 Destacar, igualmente, en esta Comunidad Autónoma la Ley 26/1997, de 26 de diciembre, por la que se crea el Instituto Madrileño de Investigación Agraria y Alimentaria. El Decreto 206/1998, de 10 de diciembre, aprueba el reglamento de funcionamiento de este Instituto. Finalmente, citar el Decreto 276/1995, de 2 de noviembre, por el que se crea el Consejo de Ciencia y Tecnología. 
DA-2003, núms. 265-266. ESTANISLAO ARANA GARCÍA. Organización administrativa de la ciencia...

Comisión Interdepartamental de Investigación y Desarrollo Tecnológico, como órgano responsable de la elaboración de los Planes Riojanos de Investigación y Desarrollo Tecnológico; el Consejo Riojano de Investigación y Desarrollo Tecnológico, como vínculo efectivo entre los agentes sociales, la comunidad científica y los responsables de la política científica y tecnológica de la Comunidad Autónoma de La Rioja; la Comisión Técnica, que será la encargada de informar y asesorar al Consejo Riojano de Investigación y Desarrollo Tecnológico y a la Comisión Interdepartamental; la Unidad Técnica, que, como su propio nombre indica, llevará a cabo la gestión administrativa de los Planes y de los Programas.

La Comunidad Autónoma extremeña no ha dictado ninguna norma general sobre investigación y desarrollo, sin embargo, destacar que existe en esta Comunidad una Consejería de Educación, Ciencia y Tecnología. Consejería que, en este caso, aglutina las competencias en materia de educación, desarrollo tecnológico, telecomunicaciones y la sociedad de la información. La Comunidad Autónoma de Castilla-La Mancha cuenta con una Consejería específica de Ciencia y Tecnología ${ }^{39}$.

En la Comunidad Autónoma de Cataluña destacar el Decreto 26/1994, de 8 de febrero, de creación de la red de centros de referencia de investigación y desarrollo de la Generalidad. Por su parte, la Orden de 8 de julio de 2001 crea el Consejo de Asesoramiento, Seguimiento y Evaluación (CASA) como órgano de la Comisión Interdepartamental de Investigación e Innovación Tecnológica para la evaluación científico-técnica, el asesoramiento y el seguimiento del III Plan de investigación de Cataluña 2001-2004.

La Comunidad Autónoma de Castilla y León ha aprobado la Ley 4/1999 de 17 de marzo, de Normas Reguladoras de la Investigación y la Ciencia. Como la propia Exposición de Motivos indica, esta Ley se desarrollará a través del correspondiente Plan de Investigación y Ciencia cuyos objetivos serán la promoción de la investigación científica básica y aplicada, la formación de los recursos humanos como base del impulso al progreso científico de la sociedad y la mejora de la competitividad de los grupos de investigación que actúan en Castilla y León. En este marco, la Ley encomienda a la Comisión Interdepartamental de Ciencia e Investigación labores de planificación, coordinación y evaluación de las políticas de Ciencia e Investigación de Castilla y León, en general, y del Plan de Investigación y Ciencia de Castilla y León, en particular. La Comisión Asesora de Investigación y Ciencia actuará como

39 Consejería creada mediante el Decreto 35/2001, de 27 de febrero. Por su parte, la Orden de 11 de febrero de 1999 crea el Consejo Asesor de la Ciencia y Tecnología. 
órgano consultivo de la Junta de Castilla y León a través de la Comisión Interdepartamental de Ciencia e Investigación, asumiendo, además, las funciones asignadas a la Comisión Asesora de Investigación y Desarrollo Científico y Técnico de Castilla y León, creada por Decreto 128/1992, de 9 de julio, por el que se regula el Apoyo y Fomento de la Investigación en Castilla y León. Por último, la responsabilidad de la ejecución y gestión del Plan de Investigación y Ciencia corresponde a las distintas Consejerías de la Junta de Castilla y León en el ámbito de sus respectivas competencias ${ }^{40}$.

En Canarias, la Ley 5/2001, de 9 de julio, de Promoción y Desarrollo de la Investigación Científica y la Innovación. Ley que se plantea como objetivos: a) la creación de una infraestructura organizativa en la Administración Pública canaria encargada de la planificación, coordinación y concentración de los recursos económicos y humanos en materia de investigación, desarrollo tecnológico e innovación en torno a objetivos definidos. En concreto, se establece la existencia de tres órganos: la Comisión de Coordinación ${ }^{41}$; la Oficina de Ciencia, Tecnología e Innovación y el Consejo Asesor; b) la implantación de un sistema de planificación que defina las líneas prioritarias de actuación en convergencia con los planes de desarrollo regional y que programe la utilización de los recursos disponibles; y c) el establecimiento de una serie de medidas de carácter complementario, dirigidas a promocionar e incentivar la investigación científica y la innovación.

Por su parte, la Comunidad Autónoma de las Islas Baleares dictó la Ley 7/1997, de 20 de noviembre, por la que se regula la Investigación y el Desarrollo Tecnológico. Ley que pretende conseguir sus objetivos de fomento de la investigación y el desarrollo tecnológico mediante los siguientes instrumentos o mecanismos: El Plan balear de investigación y desarrollo tecnológico, que es el conjunto de programas coordinados, presupuestados, priorizados y financiados que responden a la política científica y tecnológica de la Comunidad Autónoma; la Comisión Interdepartamental de Ciencia y Tecnología de las Islas Baleares y la Secretaría General del Plan balear de investigación y desarrollo tecnológico. Ambos entes elaboran y ejecutan el plan y emiten el informe al Parlamento; el Consejo Asesor de Investigación y Desarrollo Tec-

${ }^{40}$ El Decreto 37/2001, de 15 de febrero, crea la Comisión Permanente de Ciencia y Tecnología.

41 El Decreto 203/2002, de 20 de diciembre, regula la Comisión de Coordinación de Ciencia, Tecnología e Innovación y el Consejo Asesor de Ciencia, Tecnología e Innovación.

42 El Decreto 64/2000, de 7 de abril, regula el Consejo Asesor de Investigación y Desarrollo Tecnológico y el Decreto 65/2000, de 7 de abril, regula la Comisión Interdepartamental de Ciencia y Tecnología. 
nológico que es el vínculo efectivo entre los sectores productivos, la comunidad científica y los responsables de la política científica y tecnológica de la Comunidad Autónoma; los promotores como figura iniciadora de los procesos de investigación ${ }^{42}$.

La Comunidad Autónoma de Asturias ha dictado el Decreto 47/2000, de 18 de mayo, por el que se crea la Comisión Delegada para la Ciencia y la Tecnología, órgano al que le corresponden las competencias del Principado de Asturias en materia de investigación y, en particular, las siguientes: a) Elevar al Consejo de Gobierno, para su aprobación, los anteproyectos de planes regionales de investigación científica, desarrollo tecnológico e innovación; b) Evaluación de los recursos y necesidades presupuestarias y propuesta de asignación de los fondos públicos destinados a los diferentes programas de los planes regionales de investigación científica, desarrollo tecnológico e innovación; c) Seguimiento de la ejecución de los planes regionales de investigación científica, desarrollo tecnológico e innovación; d) Coordinación de las actividades de las distintas Consejerías en materia de investigación científica, desarrollo tecnológico e innovación; e) Emitir los informes que le sean solicitados por el Consejo de Gobierno o las Consejerías en materia de investigación científica, desarrollo tecnológico e innovación.

En Aragón, el Decreto 248/1995, de 26 de septiembre, creó el Consejo Superior de Investigación y Desarrollo para promover la coordinación y fomento de la investigación científica y del desarrollo tecnológico de la Comunidad Autónoma de Aragón, así como para actuar como órgano de asesoramiento del Gobierno de Aragón en dichas materias.

En Andalucía, aparte de la aprobación de los correspondientes Planes anuales de Investigación, tan sólo se ha creado, mediante la Orden de la Consejería de Salud de 21 de enero de 1998, un Comité Asesor de Ciencia e Investigación pero adscrito a dicha Consejería y, por tanto, centrando su ámbito de actuación en el sanitario. 